\title{
ESPAÇOS E VIVÊNCIAS DE LAZER NA CIDADE: construindo territórios
}

\section{SPACES AND LEISURE EXPERIENCES IN THE CITY: building territories}

\section{ESPACIOS Y VIVENCIAS DEL OCIO EN LA CIUDAD: construyendo territorios}

\author{
Isabela Veloso Lopes Versiani \\ Universidade Estadual de Montes Claros - UNIMONTES \\ E-mail: <isabelamoc@yahoo.com.br>.

Anete Marília Pereira iD
Universidade Estadual de Montes Claros - UNIMONTES
E-mail: < anete.pereira@ unimontes.br>.

RESUMO

O presente artigo, de escopo teórico a partir de pesquisa bibliográfica, tem como objetivo problematizar o lazer no cotidiano urbano a partir da compreensão e da existência de territórios para sua vivência. A categoria território tem ganhado cada vez mais destaque nos estudos que discutem o espaço e as relações de poder que nele evidenciam os agentes de sua produção e condicionam a sua apropriação. Nesse sentido, pensar os espaços de lazer como territórios nos leva a refletir sobre a própria configuração do lazer nas cidades, suas contradições e disputas. Como resultados, foram identificadas duas tendências retratadas a partir de dois espaços emblemáticos nas cidades contemporâneas: a emergência do lazer em territórios do consumo - marcada por relações capitalistas de mercado e pela dimensão econômica, como nos shoppings centers; que tem se sobreposto ao lazer em territórios da cidadania - marcado pela busca de sua efetivação como um direito social e pela dimensão política, como nos espaços públicos de praças e parques. Compreende-se, assim, que as relações entre o lazer e seus espaços urbanos como territórios são permeadas por tensões e interesses divergentes que se refletem em sua apropriação cotidiana, contribuindo para ampliar as possíveis análises entre esses dois campos.

Palavras-chave: Espaço. Território. Lazer. Consumo. Cidadania. 
VERSIANI, I. V. L.; PEREIRA, A. M.

Espaços e vivências de lazer na cidade: construindo territórios

\begin{abstract}
This article, with a theoretical scope based on bibliographical research, aims to problematize leisure in urban everyday life through the understanding and existence of territories for its experience. The territory category has gained more and more prominence in the studies that discuss the space and the relations of power that evidence the agents of its production and influence its appropriation. In this sense, thinking about leisure spaces and experiences in urban daily life leads us to reflect on the very configuration of leisure in cities, its contradictions and disputes. As results, two tendencies portrayed from two emblematic spaces in contemporary cities were identified: the emergence of leisure in territories of consumption - marked by capitalist relations of the market and by the economic dimension, like in shopping malls; which has overlapped leisure in territories of citizenship - marked by the search of its effectiveness as a social right and by the political dimension, like in public spaces such as squares and parks. It is realized, therefore, that the relations between leisure and its urban spaces as territories are permeated by divergent tensions and interests that are reflected in its daily appropriation, contributing to expand the possible analyzes between these two fields.
\end{abstract}

Keywords: Space. Territory. Leisure.Consumption.Citizenship.

\title{
RESUMEN
}

El presente artículo, de alcance teórico a partir de investigación bibliográfica, tiene como objetivo problematizar el ocio en el cotidiano urbano a partir de la comprensión y de la existencia de territorios para su vivencia. La categoría territorio ha ganado cada vez más destaque en los estudios que discuten el espacio y las relaciones de poder que en él evidencian los agentes de su producción y condicionan su apropiación. En ese sentido, pensar los espacios de ocio como territorios nos lleva a reflexionar sobre la propia configuración del ocio en las ciudades, sus contradicciones y disputas. Como resultados, se identificaron dos tendencias retratadas a partir de dos espacios emblemáticos en las ciudades contemporáneas: la emergencia del ocio en territorios del consumo - marcada por relaciones capitalistas de mercado y por la dimensión económica, como en los centros comerciales; que se ha superpuesto al ocio en territorios de la ciudadanía, marcado por la búsqueda de su efectividad como un derecho social y por la dimensión política, como en los espacios públicos de plazas y parques. Se comprende, así, que las relaciones entre el ocio y sus espacios urbanos como territorios están impregnadas por tensiones e intereses divergentes que se reflejan en su apropiación cotidiana, contribuyendo a ampliar las posibles análisis entre esos dos campos.

Palabras clave: Espacio. Territorio. Ocio. Consumo. Ciudadanía.

\section{INTRODUÇÃO}

O lazer tem sido tema de pesquisa e análise em diferentes áreas do conhecimento, com diálogos em construção no campo da Educação Física, com maior concentração, do Turismo, da Sociologia, da Antropologia, da História e outras interfaces com as Ciências 
VERSIANI, I. V. L.; PEREIRA, A. M.

Espaços e vivências de lazer na cidade: construindo territórios

Humanas, o que tem contribuído para ampliar reflexões e pontos de vista sobre um fenômeno que é fundamental para a consolidação de uma vida com mais equilíbrio e qualidade, mas que muitas vezes é tido como uma vivência carente de legitimidade, principalmente no âmbito das políticas públicas e no cotidiano urbano.

Com relação à Geografia, Mascarenhas (2010) observa uma escassez de contribuições oferecidas pelos geógrafos de forma específica, sobretudo quando analisa a trajetória do pensamento geográfico desde a tradicional escola francesa, passando pela geografia cultural alemã, pela nova geografia da década de 1950 e sua ramificação em diversas especializações e pragmatismos, ou mesmo na fase seguinte da Geografia Crítica, de inspiração marxista.

Com base nesse quadro, o autor propõe em sua análise, então, pensar as possibilidades da abordagem geográfica em torno desse tema, especialmente quando se compreende o amplo leque de atividades de lazer como práticas diversas que se relacionam com a dinâmica da acumulação do capital em meio à reprodução da sociedade, e que se difunde no tecido social a partir de uma espacialidade fundamental, baseando-se no "estudo de suas implicações e condicionantes territoriais” (MASCARENHAS, 2010, p. 141).

Diante de muitos olhares e contribuições, buscar analisar algumas das questões que envolvem o lazer, seus espaços e vivências no urbano, pressupõe, antes de tudo, reconhecer que o processo de urbanização, marcado pela industrialização e expansão do capital, produziu cidades com lógicas de apropriação do espaço e de construção de relações sociais que evidenciam aspectos contraditórios e diversos conflitos no cotidiano, destacandose implicações na produção do espaço por interesses privados hegemônicos, emergência de demandas urbanas coletivas e ações mediadoras do Estado.

A partir desse processo, o lazer também passa a ser objeto de conflito. Contrapondo a compreensão do lazer como um direito social, consolidada no plano jurídico por meio de sua presença expressa na Constituição Federal (1988) e no Estatuto da Cidade (2001), há a intensificação crescente da associação do lazer à esfera do mercado e da indústria do divertimento, na qual suas práticas e espaços são cada vez mais privatizados e convertidos em mercadoria, o que terá desdobramentos nas relações de poder e disputas que controlam o acesso, a oferta e os interesses divergentes envolvidos em suas vivências.

Nesse sentido, a categoria território pode trazer importantes contribuições. Marcada por uma estrita vinculação com o espaço e sua apropriação, a categoria território tem 
VERSIANI, I. V. L.; PEREIRA, A. M.

Espaços e vivências de lazer na cidade: construindo territórios

sido ressignificada no campo epistemológico para além de uma concepção tradicionalista, na qual estava vinculada à dimensão político-jurídica e diretamente associada ao Estado-Nação. Nesse novo debate há a ampliação da compreensão do território em direção a uma concepção mais humanista e simbólica, na qual emergem diferentes agentes e poderes que conformam a construção, desconstrução e reconstrução de territórios a partir da dimensão vivida e do cotidiano, sobretudo no espaço urbano.

Sob o prisma desta ressignificação da categoria território, o presente artigo busca problematizar algumas questões que envolvem os espaços e vivências de lazer na cidade. De natureza teórica, se desenvolveu a partir de revisão bibliográfica acerca da categoria território, tendo por base autores como Claude Raffestin (1993; 2003), Marcos Aurélio Saquet (2009), Rogério Haesbaert (2009), Marcelo Lopes de Souza (2009), Rogério Haesbaert e Ester Limonad (2007), e de estudos do lazer apoiado em autores como Nelson Carvalho Marcellino (2007), Christiane Gomes (2006), Walkíria Padilha (2006), Fernando Mascarenhas (2004), entre outros, procurando aproximar esses dois campos e identificar o processo de formação de territórios para o lazer nas cidades através das lógicas de poder predominantes que irão configurar suas principais características e formas de apropriação.

Na relação da Geografia com os estudos do lazer, essa aproximação visa ampliar o campo de análises possíveis, que vão além da descrição da localização dos espaços e possibilidades de diversas vivências de lazer pela cidade, ou da falta deles e carência de oportunidades, mas que evidenciam outras formas para se tentar compreender esse fenômeno no cotidiano e suas implicações, sobretudo nos territórios vividos, das dinâmicas de poder que conformam subjetividades e apropriações diferenciadas do espaço enquanto prática social.

\section{A CATEGORIA TERRITÓRIO E SUA INTERFACE COM O COTIDIANO: O TERRITÓRIO VIVIDO}

O território, como uma das categorias de análise da Geografia, tem sido um conceito muito utilizado por outras ciências que se interessam pelos processos de produção do espaço e compreensão de relações sociais vinculadas com a dimensão espacial, o que destaca suas possibilidades interdisciplinares; porém, justamente por essa amplitude, há também o perigo de ser utilizado apenas como um conceito da moda ou em sua superficialidade, desvinculado de eixos mais claros de entendimento. 
VERSIANI, I. V. L.; PEREIRA, A. M.

Espaços e vivências de lazer na cidade: construindo territórios

Tal alerta tem sido debatido e sistematizado por diversos autores que procuram alicerçar bases mais claras e subsídios teórico-metodológicos para estudos que trabalham com essa categoria como ponto central de análise, com destaque para a relação e diferenciação entre espaço e território; e das diferentes vertentes de abordagem conceitual possíveis, sobretudo com a aproximação nas últimas décadas do território a um conteúdo mais social de sua própria dimensão, indo além da tradição jurídico-política presente até então, principalmente relacionada às fronteiras e limites de caráter estatal; ou de estratégias de desenvolvimento econômico territorial-regional (CAPEL, 2016; FERNANDES, 2009; HAESBAERT, 2009; SAQUET, 2009).

Consenso entre a maioria dos autores, Claude Raffestin (1993) adquire centralidade nesse debate sobre o território ao incorporar, necessariamente, uma diferenciação entre o espaço e o território permeada pela ação humana. Nas palavras do autor:

\footnotetext{
É essencial compreender bem que o espaço é anterior ao território. O território se forma a partir do espaço, é resultado de uma ação conduzida por um ator sintagmático (ator que realiza um programa) em qualquer nível. Ao se apropriar de um espaço, concreta ou abstratamente (por exemplo, pela representação), o ator 'territorializa' o espaço (RAFFESTIN, 1993, p.143).
}

No mesmo sentido, Saquet (2009) assinala que embora tal diferenciação seja necessária, é fundamental reconhecer que espaço e território não estão separados; um está no outro, sendo o espaço indispensável para a apropriação e produção do território. Nessa relação, Medeiros (2009) destaca que espaço e território não podem ser dissociados: na verdade, há uma interdependência entre os mesmos, no qual o espaço precisa existir para demarcar a existência do território, que por sua vez é a condição para que o espaço se humanize. Aproximando-se de uma compreensão de que território é também um espaço de identidade, a mesma autora destaca o valor que o sentimento terá na constituição de sua base e sua expressão mais humana como lugar de mediação entre os homens e sua cultura, instaurando um novo paradigma acerca do território com funções geográficas, sociais e políticas, e como campo de representações e valores.

Assim, o território não é algo dado, mas é o espaço transformado pela ação humana, o que amplia sua correspondência não apenas a uma dimensão física ou de sua natureza material propriamente dita, ou como instrumento de domínio ou controle político estatal, mas que o aproxima de aspectos sociais, culturais e simbólicos nesse processo. 
VERSIANI, I. V. L.; PEREIRA, A. M.

Espaços e vivências de lazer na cidade: construindo territórios

Para além de uma abordagem na qual o território é utilizado como superfície, base ou palco das relações sociais, fundamental será compreender "como as diferenciações da produção espacial e territorial são organizadas e reproduzidas e por quais relações sociais", destacando-se a permanente conflitualidade dessas relações (FERNANDES, 2009, p. 199). Esse ponto configura um segundo aspecto a ser considerado nas abordagens que problematizam o território, sendo o mesmo definido a partir e por relações de poder. Para Raffestin (1993), o território será uma produção a partir do espaço e, justamente por envolver a produção, será acompanhado de um conjunto de relações que se inscrevem num campo de poder. Para esclarecer:

\begin{abstract}
$\mathrm{Al}$ integrarse en sistemas de acciones, las relaciones sociales como parte del espacio penetran todo aquello en lo que interviene la acción de los seres humanos. Cuando la abstracción del espacio cobra vida en la figura del territorio, se perciben materializadas todas las relaciones que establecen los hombres y mujeres en la formación de las sociedades, por el territorio se van a desplazar las acciones de tipo político, social, económico, o cultural, pero estas relaciones reproducen también una condición de apropiación, de dominio, de explotación. En el território estarán presentes las relaciones de poder que se organizan em una época determinada (LLANOS- HERNANDEZ, 2010, p. 217).
\end{abstract}

Assim, Souza (2009, p.60) destaca que o que define território é o poder enquanto um "campo de forças", no sentido de compreender "quem domina ou influencia e como domina ou influencia um determinado espaço", explicitando conflitos e contradições sociais. Segundo o autor, tal concepção vai além de uma projeção espacial do poder (as fronteiras e a malha territorial) e os objetos geográficos materiais, mas permite observar o que se passa com o cotidiano dos indivíduos e grupos sociais, experimentando realidades espaço-temporais bem diferentes da aparente fixidez das fronteiras estatais.

Em uma perspectiva relacional do território, Haesbaert e Limonad (2007, p. 42) explicitam que:

[...] o território não deve ser confundido com a simples materialidade do espaço socialmente construído, nem com um conjunto de forças mediadas por esta materialidade. O território é sempre, e concomitantemente, apropriação (num sentido mais simbólico) e domínio (num enfoque mais concreto, político econômico) de um espaço socialmente partilhado (e não simplesmente construído).

Para Haesbaert (2009, p. 105) na interdependência entre espaço e território, o espaço seria a expressão de uma dimensão da sociedade, em sentido amplo, que prioriza os processos em sua coexistência/simultaneidade, inclusive com a própria transformação da 
VERSIANI, I. V. L.; PEREIRA, A. M.

Espaços e vivências de lazer na cidade: construindo territórios

natureza; e o território, no interior dessa dimensão espacial, tem seu foco nas problemáticas de caráter político ou que envolvem a manifestação/realização das relações de poder, em suas múltiplas esferas, "do poder mais material das relações econômico-políticas ao poder mais simbólico das relações de ordem mais estritamente cultural”.

A partir do exposto, destaca-se que a noção de território deve partir de três pressupostos: é necessário distinguir território e espaço, muito mais amplo; o território é uma construção histórica e, portanto, social, a partir das relações de poder (concreto e simbólico) que envolvem sociedade e espaço; o território possui tanto uma dimensão mais subjetiva, como uma consciência, apropriação ou mesmo, em alguns casos, identidade territorial, e uma dimensão mais objetiva, ligada a dominação do espaço em um sentido mais concreto, realizada por instrumentos de ação político-econômica (HAESBAERT; LIMONAD, 2007).

O quadro 01, elaborado por Haesbaert e Limonad (2007), sintetiza a discussão desenvolvida até aqui e esclarece alguns dos pontos abordados, no qual se explicita as diferentes concepções de território a partir de três linhas de abordagem conforme a dimensão social priorizada, na qual destacamos para as análises que se seguem, a emergência da dimensão cultural.

Embora a dimensão jurídico-política tenha sido a mais enfatizada nos últimos tempos, é na relação com a dimensão cultural que se tem desenvolvido uma releitura do território, mais próxima de uma vertente simbólica e subjetiva, na qual o território passa a ser visto, sobretudo, como produto da apropriação/valorização simbólica de um grupo em relação ao seu espaço vivido (HAESBAERT, 2009).

Ao se aprofundar nos estudos que abordam o território vivido, Paula (2009, p.3) enfatiza que o que está na base de todos é a compreensão de que:

[...] o território é perscrutado a partir da vivência dos indivíduos. O que funda estes territórios é a interação diária entre as pessoas e das relações destas com o espaço; e deste ponto deriva a relevância da subjetividade e intersubjetividade, do conhecimento experiencial e intuitivo dos indivíduos que passam a ser meio de compreensão destes territórios.

Na mesma linha, Raffestin (2003) caracteriza o território do cotidiano como aquele que corresponde à territorialização de nossas ações todos os dias, através do qual garantimos a satisfação das necessidades; em que há relações entre os indivíduos e lugares; território da tensão e da distensão, de uma territorialidade imediata, banal e original, previsível e imprevisível. 
VERSIANI, I. V. L.; PEREIRA, A. M.

Espaços e vivências de lazer na cidade: construindo territórios

Quadro 01: Abordagens conceituais de território em três vertentes básicas

\begin{tabular}{|c|c|c|c|c|c|c|}
\hline \multirow{2}{*}{$\begin{array}{l}\text { Dimensaio } \\
\text { Privilegiada }\end{array}$} & \multirow{2}{*}{$\begin{array}{c}\text { concepcōes } \\
\text { correlatas }\end{array}$} & \multirow{2}{*}{$\begin{array}{l}\text { concepçáo de } \\
\text { território }\end{array}$} & \multicolumn{2}{|c|}{ territorializaçăo } & \multirow{2}{*}{$\begin{array}{c}\text { perspectiva } \\
\text { da } \\
\text { Geografia }\end{array}$} & \multirow{2}{*}{$\begin{array}{c}\text { exemplos de } \\
\text { trabalhos } \\
\text { próximos a } \\
\text { esta vertente }\end{array}$} \\
\hline & & & $\begin{array}{c}\text { principais } \\
\text { atores/ agentes }\end{array}$ & $\begin{array}{l}\text { principais } \\
\text { vetores }\end{array}$ & & \\
\hline $\begin{array}{l}\text { juridico- } \\
\text { politica } \\
\text { (majoritária, } \\
\text { inclusive no } \\
\text { âmbito da } \\
\text { Geografia) }\end{array}$ & $\begin{array}{l}\text { - Estado-nação } \\
\text { - fronteiras } \\
\text { politicas e } \\
\text { limites politico- } \\
\text { administrativos }\end{array}$ & $\begin{array}{l}\text { um espaço } \\
\text { delimitado e } \\
\text { controlado sobre / } \\
\text { por meio do qual se } \\
\text { exerce um } \\
\text { determinado poder, } \\
\text { especialmente o de } \\
\text { caráter estatal }\end{array}$ & $\begin{array}{l}\text { - Estado-nação } \\
\text { - diversas } \\
\text { organizações } \\
\text { políticas }\end{array}$ & $\begin{array}{l}\text { relaçōes de } \\
\text { dominação } \\
\text { politica e } \\
\text { regulação }\end{array}$ & $\begin{array}{l}\text { Geografia } \\
\text { Politica } \\
\text { (Geopolitica) }\end{array}$ & $\begin{array}{l}\text { Alliès (1980) } \\
\text { a visão } \\
\text { clássica de } \\
\text { Ratzel }\end{array}$ \\
\hline cultural(ista) & $\begin{array}{l}\text { - lugar e } \\
\text { cotidiano } \\
\text { - } \quad \text { identidade e } \\
\text { alteridade } \\
\text { social } \\
\text { - cultura e } \\
\text { imaginário } \\
\text { (imaginário: } \\
\text { "conjunto de } \\
\text { representaç̋es, } \\
\text { crenças, desejos, } \\
\text { sentimentos, em } \\
\text { termos dos quais } \\
\text { um individuo ou } \\
\text { grupo de individuos } \\
\text { vê a realidade e a } \\
\text { si mesmo") }\end{array}$ & $\begin{array}{l}\text { produto } \\
\text { fundamentalmente } \\
\text { da apropriação do } \\
\text { espaço feita através } \\
\text { do imaginário e/ou } \\
\text { da identidade social }\end{array}$ & $\begin{array}{l}\text { - individuos } \\
\text { - grupos étnico- } \\
\text { culturais }\end{array}$ & $\begin{array}{l}\text { relaçöes de } \\
\text { identificação } \\
\text { cultural }\end{array}$ & $\begin{array}{l}\text { Geografia } \\
\text { Humanistica } \\
\text { e/ou } \\
\text { Geografia } \\
\text { Cultural }\end{array}$ & $\begin{array}{l}\text { Deleuze e } \\
\text { Guattan } \\
\text { (1972) } \\
\text { Tuan (1980 e } \\
1983)\end{array}$ \\
\hline $\begin{array}{l}\text { econômica } \\
\text { (muitas vezes } \\
\text { economicista) } \\
\text { minoritária }\end{array}$ & $\begin{array}{l}\text { - divisão } \\
\text { territorial do } \\
\text { trabalho } \\
\text { - classes sociais } \\
\text { e relaç̧es de } \\
\text { produção }\end{array}$ & $\begin{array}{l}\text { (des)ternitorializa- } \\
\text { şo é vista como } \\
\text { produto espacial do } \\
\text { embate entre } \\
\text { classes sociais e da } \\
\text { relação capital- } \\
\text { trabalho }\end{array}$ & $\begin{array}{ll}\text { - } & \text { empresas } \\
\text { - } & \text { trapitalistas) } \\
\text { - } & \text { Estados } \\
\text { enquantores } \\
\text { unidades } \\
\text { econômicas }\end{array}$ & $\begin{array}{l}\text { relações } \\
\text { sociais de } \\
\text { produçẵo }\end{array}$ & $\begin{array}{l}\text { Geografia } \\
\text { Económica }\end{array}$ & $\begin{array}{l}\text { Storper (1994) } \\
\text { Benko (1996) } \\
\text { Veltz (1996) }\end{array}$ \\
\hline
\end{tabular}

Fonte: HAESBAERT; LIMONAD, 2007, p.45.

A aproximação do conceito de território ao mundo do "vivido" contribui para discernir o papel da dimensão espacial na realidade, voltada para compreender e mobilizar fatores específicos da dimensão vivida, próxima do cotidiano, das necessidades, interesses e conflitos refletidos na produção e apropriação de territórios; e também na forma como o espaço se organiza, sobretudo no meio urbano marcado pelo domínio capitalista.

O termo 'organização do espaço', que procura compreender como macro-processos (intrínsecos à matriz da dinâmica capitalista) dispõem objetos espaciais, que condicionam e são condicionados pelo modo como classes socioeconômicas se relacionam. No caso dos territórios vividos como categoria para compreender a organização do espaço, estamos falando do modo como os indivíduos vivem e 'funcionalizam' cotidianamente este espaço (PAULA, 2009, p.7).

Nesse aspecto, diferentes grupos/classes irão conformar uma identidade territorial, o que pressupõe também discutir a identidade social e a sociedade, "discutir imaginários sobre as pessoas e esse território e, consequentemente, apreender como os indivíduos (os que vivem 
VERSIANI, I. V. L.; PEREIRA, A. M.

Espaços e vivências de lazer na cidade: construindo territórios

ou não o território) concebem e agem (em todos os sentidos: políticos, sociais) em relação a ele" (PAULA, 2009, p.8).

Como síntese de um levantamento no Brasil de alguns trabalhos teóricos e empíricos que usaram a categoria território de acordo com essa dimensão vivida, a referida autora sistematiza quatro eixos que estruturam essa perspectiva (Quadro 2).

\begin{tabular}{|c|c|c|c|c|}
\hline Agente & $\begin{array}{l}\text { Morfologia, } \\
\text { configuração } \\
\text { temitorial }\end{array}$ & $\begin{array}{l}\text { Mote da } \\
\text { ternitorialização }\end{array}$ & $\begin{array}{l}\text { Indicação teórico- } \\
\text { metodológica }\end{array}$ & $\begin{array}{l}\text { Referências } \\
\text { bibliográficas (números } \\
\text { de citaçōes no conjunto } \\
\text { dos textos) }\end{array}$ \\
\hline $\begin{array}{l}\text { grupo social; } \\
\text { grupo } \\
\text { sociocultural; } \\
\text { organizaçōes } \\
\text { populares; } \\
\text { tribos urbanas }\end{array}$ & $\begin{array}{l}\text { áreas da cidade: } \\
\text { redes dentro da } \\
\text { cidade; espaços } \\
\text { públicos da } \\
\text { cidade; bairro; } \\
\text { propriedade } \\
\text { privada } \\
\text { (campo) }\end{array}$ & $\begin{array}{l}\text { Estratégia; expressão } \\
\text { do imaginário: } \\
\text { sobrevivência; } \\
\text { satisfaçâo de } \\
\text { necessidades; } \\
\text { "institucionalizaçāo" } \\
\text { de grupo }\end{array}$ & $\begin{array}{l}\text { Subjetividade; } \\
\text { apropriaçåo } \\
\text { simbólica; } \\
\text { sentimento; vinculo } \\
\text { afetivo; } \\
\text { representação social; } \\
\text { comportamento e } \\
\text { relaçōes sociais }\end{array}$ & $\begin{array}{l}\text { Claude Raffestin (4); Robert } \\
\text { Sack (3); Marcelo L Souza } \\
\text { (3); Rogério Haesbaert (3); } \\
\text { Felix Guatari (2); Zilá } \\
\text { Mesquita (1); Joel } \\
\text { Bonnermason (1); } \\
\text { Gui DiMeo (1); Roberto L } \\
\text { Correa (1); Frederich Ratzel } \\
\text { (1); Rosa Moura e Clovis } \\
\text { Ultramra (1); } \\
\text { Paul Claval (1) }\end{array}$ \\
\hline
\end{tabular}

Fonte: PAULA, 2009, p. 7.

Evidencia-se que a perspectiva do território vivido mobiliza diferentes agentes coletivos para compreender processos que se dão em diversos espaços, sobretudo em relação às configurações de um modo de vida urbano e das inter-relações possíveis que levam a constituição de territórios mais próximos da esfera dos sujeitos que os vivenciam cotidianamente.

Paula (2009, p.10) ainda destaca que a relação entre a cidade e os territórios vividos, majoritariamente, se desenvolve no espaço público, teoricamente acessível a todos e no qual há certa liberdade de ações em concomitância com códigos de conduta e processos de territorializações que tornam mais ou menos exclusivas porções deste espaço, "como grupos apropriando praças, esquinas, áreas de parques ou shoppings, ruas, bairros ou espaços que estão na interface público-privado, como bares, clubes".

Será no território enquanto categoria de análise do vivido, que se evidenciam a rede de relações sociais e os campos de força, no qual um mesmo território pode ter diferentes significados das vivências, sentimentos e percepções que irão influenciar seus usos e representações. No caso do lazer, este movimento de territorialização de diferentes espaços expõe, nas cidades, conflitos e desigualdades, sobretudo na relação dos espaços públicos em 
VERSIANI, I. V. L.; PEREIRA, A. M.

Espaços e vivências de lazer na cidade: construindo territórios

contraposição aos espaços privados disponíveis para sua vivência e a partir de diferentes formas de apropriação, o que possibilita ampliar sua compreensão e apontar novas abordagens de análise.

\section{OS MÚlTiPlos TERRITÓRIOS DO LAZER NA CIDADE: DO CONSUMO À CIDADANIA}

A inserção da preocupação com questões referentes ao lazer, especialmente nas cidades, é fundamental para problematizar a relação que esse moderno fenômeno estabelece não só com as categorias de trabalho e tempo, mas, principalmente, com o espaço e o predomínio da lógica capitalista em interface com o mercado em suas práticas e manifestações, o que o distancia cada vez mais de sua dimensão enquanto um direito social na contemporaneidade.

Para Mascarenhas (2010), p.151 “o lazer vem se tornando um poderoso instrumento de valorização do espaço, favorecendo o grande capital imobiliário e acentuando a natureza segregacionista da urbanização contemporânea", com desdobramentos em diferentes processos por meio da valorização e elitização dos espaços de consumo turístico; projetos de revitalização de áreas centrais; proliferação de condomínios fechados com lazer completo e "seguro"; uso do lazer como city marketing, dentre outros.

Assim, os espaços de lazer na cidade serão marcados pela influência de diferentes agentes na sua produção, o que perpassa ações diretas do mercado e dos interesses imobiliários, do Estado e da própria mobilização social e comunitária nas disputas pela sua produção, seu consumo e por sua legitimação democrática na sociedade, e resulta em uma compreensão desses espaços que vai muito além de sua materialidade física, incorporando aspectos sociais, culturais, políticos e econômicos.

Nesse sentido, uma definição pertinente é exposta por Dumazedier (1974, p.1701) que define o espaço de lazer, então, como um espaço social no qual acontecem relações específicas entre seres, grupos, meios e classes. Para ele:

[...] este espaço é determinado pelas características da população que o utiliza, pelo modo de vida dos diferentes meios sociais que o frequentam. Deverá ao mesmo tempo respeitar, desenvolver as diversidades culturais destes indivíduos para escapar à uniformização, à padronização, ao tédio social. Deverá também reduzir as 
VERSIANI, I. V. L.; PEREIRA, A. M.

Espaços e vivências de lazer na cidade: construindo territórios

diferenças, as disparidades, os desequilíbrios culturais que privam algumas esferas sociais de tudo o que a cultura urbana poderia lhes proporcionar.

Assim, no processo para a compreensão do lazer, é fundamental perceber, como evidenciado por Padilha (2006, p.12), que a sociedade não é harmônica, mas permeada por contradições e conflitos, formada por classes sociais distintas, cujas condições materiais determinam, não só a existência, mas também a forma de lazer de cada classe, em que "não há o mesmo lazer para todos, ainda mais porque, na sociedade capitalista, tudo é potencialmente transformado em mercadoria, inclusive o lazer que passa a ser comprado e vendido no mercado". No contexto urbano, a interação desse lazer com a vida social, com as características das cidades e com os espaços disponíveis para sua prática problematiza sua vivência a partir da desigualdade de condições materiais ao seu consumo, da dificuldade de acesso a suas práticas, enfim, das oportunidades escassas que o meio urbano oferece para o desenvolvimento de outro tipo de lazer que não seja transformado em mercadoria para a grande maioria da população.

Essa situação é vista com clareza por Gomes (2006, p.179), ao afirmar que “o lazer se mescla com o consumo e, aos direitos de cidadania, se sobrepõem os direitos de consumidor". É difícil encontrar nas cidades opções de lazer que não envolvam gastos substanciais, além das muitas dificuldades para acessá-las. Na lógica da sociedade de consumo, o que passa a ser valorizado no lazer cotidiano não são atividades populares que fomentam o encontro, o convívio, a discussão, a participação, etc., mas aquelas que possibilitam o consumo de diversas mercadorias, dentre elas, as manifestações culturais e esportivas desenvolvidas naqueles espaços em que o direito ao lazer é substituído pelo ato de consumir (CASTELLANI FILHO, 2006).

No mesmo contexto, Mascarenhas (2004) ao expor a desintegração do direito ao lazer em sua essência, destaca que o problema do direito de consumidor se sobrepor aos chamados direitos de cidadania leva o lazer a se manifestar como objeto de conquista no mercado. Nesse sentido, o autor afirma que:

[...] os bens e serviços de lazer tornam-se acessíveis apenas para uma minoria, apresentando-se como um tipo muito específico de propriedade. Somente de posse desse 'direito', adquirido numa relação de compra e venda efetuada no mercado, nem sempre de modo direto, que o cidadão-consumidor, como 'proprietário', pode valer-se do direito ao consumo, usufruindo, desfrutando, fruindo ou gozando de um determinado complexo de experiências lúdicas proporcionadas por aquilo que doravante convencionaremos chamar por 'mercolazer', forma contemporânea e 
VERSIANI, I. V. L.; PEREIRA, A. M.

Espaços e vivências de lazer na cidade: construindo territórios

tendencial de manifestação do lazer como mercadoria (MASCARENHAS, 2004, p.8).

Essa perspectiva refletida na dimensão espacial irá expor que é cada vez mais visível nas cidades a falta de espaços públicos para o lazer e o predomínio da oferta de espaços e equipamentos para o lazer mercadoria. Marcellino (2007, p.19) complementa esse pensamento ao dizer que "se o lazer é colocado pela sociedade capitalista enquanto um momento de consumo, o espaço para o lazer também é visto como um espaço para o consumo", seguindo uma tendência que leva à privatização de seus equipamentos, espaços de convívio e áreas verdes.

Diante desse quadro, se a construção de territórios passa por uma relação com o espaço e com o campo de forças de poder que determinam sua produção, o questionamento proposto por Souza (2009) - sobre quem domina ou influencia e como domina e influencia o espaço - evidencia no debate sobre o lazer e seus territórios, a sobreposição da lógica capitalista na conformação de territórios para o seu consumo em detrimento dos territórios para sua vivência democrática e cidadã.

No campo de forças que configuram a produção de territórios para o lazer, a disputa de poder não é justa, e nem poderia ser. Fundamentada em bases capitalistas, o mercado se apropria cada vez mais dos espaços disponíveis para o lazer, restringindo sua vivência enquanto possibilidade de consumo e tendo a centralidade na dimensão econômica como prática hegemônica.

Assim, os territórios para o lazer enquanto consumo se multiplicam na configuração espacial das cidades ao mesmo tempo em que excluem grande parte da população de suas vivências, sendo o Shopping Center um dos exemplos mais emblemáticos de um território do lazer nesses moldes. Não são os sujeitos que se apropriam do espaço de lazer como forma de emancipação e liberdade, mas se submetem no espaço de lazer à lógica de poder do mercado e aos ditames de uma sociedade de consumo de massa.

Os Shoppings Centers como templos de consumo são um fenômeno que tem aumentado em ritmo acelerado, não só nas capitais, mas também em cidades médias no Brasil e pelo mundo, nos quais há a concentração e centralização da atividade de lazer com menor diversidade e maior custo como características, sendo que "o lugar do lazer na maioria das cidades 'modernas' é o shopping”, conferindo ao binômio lazer e consumo uma inesgotável 
VERSIANI, I. V. L.; PEREIRA, A. M.

Espaços e vivências de lazer na cidade: construindo territórios

fonte para o capitalismo (MARIN, 2018, p. 81). Além desse aspecto, na relação com o tempo o mesmo autor destaca que:

O shopping transforma o tempo livre em tempo de consumo. Como espaço privado, estabelece condições de apropriação do espaço público (uma praça, um teatro, uma rua). Ele retira o cidadão do espaço público, de qualquer participação e mobilização [...] O shopping não é acessível aos recém-chegados e passa a ter frequentadores específicos, com regras e rituais de aproximação e inserção, baseados em códigos e hierarquias (MARIN, 2018, p. 84).

Em sentido semelhante, ao analisar o vasto leque de relações entre poder, espaço e lazer a partir de reflexões em torno dos estádios de futebol e das mudanças recentes desse equipamento de uso coletivo a partir de "uma estratégia de elitização e controle acentuado dos corpos, em uma perspectiva foucaultiana”, Mascarenhas (2010, p. 153; p. 155) expõe que "o novo estádio assemelha-se a outros espaços padronizados e previsíveis da vida social: um Shopping Center, um teatro, uma sala de estar, reinos do individualismo e da passividade, que interessam ao capitalismo, que se inscrevem numa generalizada microfísica do poder" como forma de controle, alienação e exclusão.

No outro extremo, evidenciam-se as possibilidades de vivência contrahegemônica do lazer, na qual o espaço público assume centralidade para ser apropriado e transformado em um território do lazer para a cidadania, na qual a cidade e seus espaços são pensados dentro de uma dimensão ampla e humana, que, para além da sua materialidade física ou mercantil, se corporifica a partir dos próprios sujeitos envolvidos nas relações sociais que acontecem em seu espaço cotidiano e nas suas possibilidades de inclusão, convivência e emancipação.

Ao discorrer sobre os espaços públicos e suas variações no tempo e no espaço, Gomes (2018) destaca a importância da dimensão política da atividade pública, que se associa diretamente ao cotidiano desses espaços, mas que não está presente sempre da mesma maneira, sendo necessária uma observação cuidadosa dos usos desses espaços para aprendermos a distinguir os diversos graus da expressão política desse público por meio dos comportamentos e regulações que abrigam. Para esclarecer seu posicionamento acerca dos espaços públicos, o autor enfatiza que:

Muito embora seja uma forma material, não há um desprezo pelo alcance político desses espaços, ao contrário. Compreendemos essa esfera política dentro do universo das práticas cotidianas que se constroem sobre eles. Uma sociedade democrática não se exprime somente pelas leis e instituições que a regulamentam: 
VERSIANI, I. V. L.; PEREIRA, A. M.

Espaços e vivências de lazer na cidade: construindo territórios

ela tem outra importantíssima medida, frequentemente menosprezada, aquela da vivência da ordem pública nos espaços de vida em comum, nos espaços públicos. Para isso, nada melhor do que conhecer esses espaços em sua banal dinâmica cotidiana. Os ritos de sociabilidade vivida sobre esses espaços são um exercício e uma celebração da vida social pública e sua observação nos oferece os instrumentos para reconhecer diferentes graus de convivência democrática em variados ambientes da cidade (GOMES, 2018, p.358).

Buscando fazer com que a cidadania de fato faça parte da cidade e incorporando a categoria do território vivido aqui discutida, o espaço de lazer passa a se caracterizar como “espaço de encontro, convívio, do encontro com o 'novo' e com o diferente, lugar de práticas culturais, de criação, de transformação e de vivências diversas, no que diz respeito a valores, conhecimentos e experiências" (GOMES, 2006, p.73). Na relação com a dimensão espacial das cidades, os espaços públicos como praças ou parques transformados em territórios do lazer para a cidadania tornam-se fundamentais para combater a mercadorização do lazer no ambiente urbano. Vinculado à esfera da vida, de seus valores humanos e de suas potencialidades sociais, o lazer e seus espaços públicos são essenciais para o desenvolvimento de outra lógica nos processos de territorialização nas cidades, aproximando-o de uma vivência mais democrática.

Nesse sentido, segundo Mascarenhas (2010, p.156), embora o lazer, "como um tema aparentemente leve e ingênuo", possa "esconder uma poderosa engrenagem de lucro e poder", ele também "pode exprimir, numa perspectiva lefebvreana, as iniciativas populares de insurreição, por meio do uso que instaura novas territorialidades". Desse contexto, emerge a necessidade de se pensar outras lógicas para a produção do espaço, na qual a busca pela efetivação do direito à cidade nos moldes pensados por Lefebvre (2001) abre caminhos na direção de uma maior articulação política e social, que pode ser potencializada pela compreensão da cidade como obra e vida, na qual o cotidiano e o lazer se constituem como elementos importantes para impulsionar outras perspectivas e possibilidades de resistência frente ao domínio do capital que se impõe ao modo de viver urbano.

A partir do momento em que o espaço público de lazer é incorporado na experiência cotidiana do indivíduo e adquire um significado, a apropriação desse bem comum público passa a não ser tarefa exclusiva do Poder Público, mas se expande para os sujeitos de determinada comunidade ou grupo social, que também se sentem responsáveis por ocupar e cuidar desse espaço agora territorializado, transformando-o em um território de lazer para a cidadania e aproximando-o de uma dimensão política, permeada por subjetividades 
VERSIANI, I. V. L.; PEREIRA, A. M.

Espaços e vivências de lazer na cidade: construindo territórios

individuais, mas, também, por sentimentos de identidade coletiva com o espaço público, no qual o controle desse espaço pertencente a todos e pode ser apropriado por todos.

Nesses territórios vividos, são os próprios sujeitos, auxiliados ou não pelo Poder Público por meio de políticas públicas setoriais, que determinam e constroem relações para efetivação do lazer como um direito social, transformando os espaços e equipamentos públicos de lazer em territórios para a cidadania, com centralidade na dimensão política e social de sua apropriação, na qual esses territórios passam a ser um espaço de encontro, convívio, liberdade e emancipação.

Gomes (2006, p.181-2) complementa essa realidade dizendo que é possível, por meio de ações e inserções mais comprometidas com a construção de uma nova sociedade, mais justa, solidária e humana, buscar "humanizar" a cidade. Para ela, a cidade, em vez de ser orientada apenas pelo desempenho do trabalho, necessita "expandir as possibilidades para que o lazer possa ser usufruído por todos os seus habitantes, com dignidade e criticidade, valorizando o ser humano que a constitui ao mesmo tempo em que é constituído". A autora ainda diz que o lazer pode deixar de ser restrito a um consumo alienado, para se transformar de fato em uma prática social que representa uma das dimensões da vida em sociedade.

Dessa forma, para sintetizar a interface proposta por esse artigo, destaca-se o pensamento de Mascarenhas (2010, p.157), no qual o lazer em interface com a Geografia deve ser considerado um tema muito sério, que perpassa a compreensão de diferentes fenômenos e tendências de sua inserção na dinâmica socioespacial de acumulação do capital e reprodução social, podendo "abrir novas portas para o entendimento do mundo, descortinando sutis mecanismos de exploração, modernas estratégias de poder, mas também possibilidades de emancipação".

\section{CONSIDERAÇÕES FINAIS}

Conforme discutido, o espaço, a partir do momento em que é usado e apropriado se transforma em território, permeado por relações de poder, que perpassam desde a esfera político-jurídica (como a formação do Estado-Nação ou de diferentes escalas no âmbito federal, estadual ou municipal); bem como do campo econômico, sendo determinante nas estratégias de desenvolvimento territorial - regional; e, por fim com base em uma dimensão cultural e simbólica (dos sentidos e significados daquele espaço no cotidiano). 
VERSIANI, I. V. L.; PEREIRA, A. M.

Espaços e vivências de lazer na cidade: construindo territórios

A releitura do território que vem sendo proposta com base nessa última dimensão contribui para pensar o espaço em estreita relação com os sujeitos que, a partir de sua apropriação, o transformam em território vivido, retratando representações, necessidades, conflitos e disputas de poder no processo de sua configuração cotidiana, permeado por subjetividades e identidades.

Relacionada ao lazer, a abordagem aqui desenvolvida buscou explicitar o campo de disputas de poder em torno de seus espaços, evidenciando que os múltiplos territórios para/do lazer na cidade podem se constituir a partir da afirmação de uma lógica de consumo de massa, centrada na dimensão econômica e na exclusão de grande parte da população em suas vivências cotidianas - os territórios do lazer enquanto consumo; ou como um meio de efetivação do lazer como direito social, no qual seus espaços públicos ganham centralidade na dimensão política como espaço de encontro, convívio, liberdade e emancipação - os territórios do lazer para a cidadania, ainda em construção, que tem como alicerce a busca pela efetivação do direito à cidade, apesar dos muitos desafios cotidianos que se entrecruzam nessa direção.

Ao se aproximar a lógica capitalista da produção do espaço ao campo do lazer, torna-se evidente que as disputas de poder em torno dos espaços de lazer nas cidades e suas diversas possibilidades de territorialização têm sido marcadas pela hegemonia do espaço privado em detrimento do espaço público, assim como de uma apropriação individual via consumo em detrimento de uma apropriação coletiva e cidadã.

Assim, pensar o lazer e seus espaços na cidade a partir da relação com a categoria território é um desafio que dialoga com novos olhares, sentidos e significados desse fenômeno no cotidiano urbano, ampliando a possibilidade de estudos na área em direção a sua melhor compreensão, priorizando contribuições de forma interdisciplinar a serem aprofundadas, principalmente na relação com os territórios vividos.

\section{REFERÊNCIAS}

BRASIL. Constituição da República Federativa do Brasil (1988). Promulgada em 5 de outubro de 1988. Obra coletiva de autoria da Editora Saraiva. São Paulo: Saraiva, 2006.

BRASIL, Congresso Nacional. Lei n. 10.257 de 10 de julho de 2001(Estatuto da Cidade). Regulamenta os arts. 182 e 183 da Constituição Federal, estabelece diretrizes 
VERSIANI, I. V. L.; PEREIRA, A. M.

Espaços e vivências de lazer na cidade: construindo territórios

gerais da política urbana e dá outras providências. Disponível em:

<http//www.planalto.gov.br/CCIVIL/LEIS_2001/L10257.htm> Acesso em: 10 maio 2008.

CAPEL, H. Las ciencias sociales y el estudio del território. Biblio 3W. Revista Bibliográfica de Geografia y Ciencias Sociales. Barcelona: Universidad de Barcelona. v. XXI, n. 1.149, 2016.

CASTELLANI FILHO, L. Gestão Municipal e política de lazer. In: YSAYAMA, Helder; LINHALES, Meily. (org.) Sobre lazer e política: maneiras de ver, maneiras de fazer. Belo Horizonte: Editora UFMG, 2006. p.119-135.

DUMAZEDIER, J. Sociologia Empírica do Lazer. São Paulo: Editora Perspectiva, 1974. 244 p.

FERNANDES, B. Sobre a tipologia de territórios. In: SAQUET, M.; SPOSITO, E. (org.). Territórios e territorialidades: teorias, processos e conflitos. São Paulo: Expressão Popular: UNESP: Programa de Pós Graduação, 2009. p.197-215.

GOMES, C., Lazer e Cidade: reflexões. In: BRANDÃO, C. (org.). As Cidades da Cidade. Belo Horizonte: Ed. UFMG, 2006. p. 171-184.

GOMES, P. Considerações acerca dos espaços públicos e suas variações no tempo e no espaço. In: SERPA, A.; CARLOS, A. (org.). Geografia Urbana: desafios teóricos contemporâneos. Salvador: EDUFBA, 2018. p. 351 -375.

HAESBAERT, R. Dilema de conceitos: espaço-território e contenção territorial. In: SAQUET, M.; SPOSITO, E. (org.). Territórios e territorialidades: teorias, processos e conflitos. São Paulo: Expressão Popular: UNESP: Programa de Pós Graduação, 2009. p. 95 120.

HAESBAERT, R; LIMONAD, E. O território em tempos de globalização. Etc...., espaço, tempo e crítica. Rio de Janeiro: UFF. v. 1, n.2(4), p.39-52, ago. 2007.

LEFEBVRE, H. O direito à cidade. São Paulo: Centauro, 2001. 146 p.

LLANOS-HERNANDEZ, L. El concepto del territorio y la investigación en las ciencias sociales. Agricultura, sociedad y desarrollo. México. v. 7, n. 3, p. 207-220, set. 2010.

MARCELLINO, N. Introdução. In: MARCELLINO, N. et al. Espaços e equipamentos de lazer em região metropolitana: o caso da RMC - Região Metropolitana de Campinas. Curitiba: Opus, 2007. p.10-28.

MASCARENHAS, F. "Lazerania" também é conquista: tendências e desafios na era do mercado. Movimento, Porto Alegre, v. 10, n. 2, p. 73-90, maio/ago. 2004. Disponível em: http://boletimef.org/?canal=12\&file=897 . Acesso em: 10 jan. 2008.

MASCARENHAS, G. Contribuições da Geografia para o Estudo do Lazer. In: MELO,V. (org.) Lazer: olhares multidisciplinares. Campinas: Editora Alínea, 2010. p. 139-160. 
VERSIANI, I. V. L.; PEREIRA, A. M.

Espaços e vivências de lazer na cidade: construindo territórios

MARIN, R. Práticas sociais de lazer nas cidades amazônicas: pesquisas como requisito para políticas públicas. In: CHAAR, B. (org.) Novas leituras do lazer contemporâneo. Belém: NAEA, 2018. p.75-89.

MEDEIROS, R. Território, Espaço de Identidade. In: SAQUET, M.; SPOSITO, E. (org.) Territórios e territorialidades: teorias, processos e conflitos. São Paulo: Expressão Popular: UNESP: Programa de Pós Graduação, 2009. p.217-227.

PADILHA, W. Introdução. In: PADILHA, W (org.). Dialética do Lazer. São Paulo: Cortez, 2006. p.9-18

PAULA, F. C. Repensando o território: discutindo a categoria de território vivido. Anais do II Encontro Nacional de História do Pensamento Geográfico. 2009, São Paulo. Disponível em: https://enhpgii.wordpress.com/trabalhos/ . Acesso em: 10 ago. 2017.

RAFFESTIN, C. Por uma Geografia do Poder. São Paulo: Ática, 1993. 269 p.

RAFFESTIN, C. Immagini e identitá territoriali. In: DEMATTEIS, G; FERLAINO, F. Il modo e i luoghi: geografie delle identità e del cambiamento. Torino: IRES, 2003.p.3-11.

SAQUET, M. Por uma abordagem territorial. In: SAQUET, M; SPOSITO, E. (org.) . Territórios e territorialidades: teorias, processos e conflitos. São Paulo: Expressão Popular: UNESP: Programa de Pós Graduação, 2009. p 73- 94.

SOUZA, M. L. O território: sobre espaço e poder, autonomia e desenvolvimento. In:

CASTRO, I. et al. (org.). Geografia:conceitos e temas. Rio de Janeiro: Bertrand Brasil, 1995.

SOUZA, M. L."Território" da divergência (e da confusão): em torno das imprecisas fronteiras de um conceito fundamental. In: SAQUET, M.; SPOSITO, E. (org.) Territórios e territorialidades: teorias, processos e conflitos. São Paulo: Expressão Popular: UNESP: Programa de Pós Graduação, 2009. p. 57 -72. 
Isabela Veloso Lopes Versiani - Possui Graduação em Educação Física, Graduação em Ciências Sociais e Mestrado em Desenvolvimento Social, todos cursados pela Universidade Estadual de Montes Claros (UNIMONTES). Atualmente é Professora do Departamento de Educação Física e do Desporto (UNIMONTES) e cursa Doutorado em Desenvolvimento Social pelo Programa de Pós-Graduação em Desenvolvimento Social da Universidade Estadual de Montes Claros (UNIMONTES).

Anete Marília Pereira - Possui Graduação em Geografia pela Universidade Estadual de Montes Claros (UNIMONTES), Mestrado em Geografia pela Universidade Federal de Minas Gerais (UFMG) e Doutorado em Geografia pela Universidade Federal de Uberlândia (UFU). Atualmente é Professora do Programa de Pós-Graduação em Geografia do Departamento de Geociências e do Programa de Pós-Graduação em Desenvolvimento Social, ambos da Universidade Estadual de Montes Claros (UNIMONTES).

Artigo recebido em: 17 de setembro de 2018.

Artigo aceito em: 24 de junho de 2019.

Artigo publicado em: 18 de outubro de 2019. 